\title{
J. S. BACH'IN BWV 881 FA MINÖR PRELÜD VE FÜGÜNÜN ANALIZi VE EĞiTSEL AÇIDAN ÖNERILER
}

\author{
THE ANALYSIS AND EDUCATIONAL-BASED SUGGESTIONS OF J.S. BACH'S BWV F MINOR \\ PRELUDE AND FUGUE
}

\author{
Nilüfer Özer ${ }^{*}$ R. Erol Demirbatır ${ }^{* *}$
}

\begin{abstract}
Öz
Bu çalışmada, Johann Sebastian Bach (1685-1750)'ın “ iyi Düzenlenmiş Klavye için 48 Prelüd ve Füg” adlı eserinin eğitsel hedeflere uygunluğunun saptanması kapsamında Fa Minör BWV 881 Nolu Prelüd ve Füg'ün müziksel analizi yapılmış ve piyano eğitimi bakımından eğitici özelliklerinin ortaya konulması amaçlanmıştır.

Genel bir bakışla, "Iyi Düzenlenmiş Klavye İçin 48 Prelüd ve Füg” ün eğitsel amaçlarla yazılmış bir eser olması, prelüd ve füg formu niteliği taşıması, ayrıca piyano eğitiminde teknik bir başyapıt olarak ele alınıyor olması gibi nedenlerle, piyano literatürünün temel yapı taşlarından biri olduğu kabul edilmektedir. "iyi Düzenlenmiş Klavye İçin 48 Prelüd ve Füg” Barok müziğin stilistik, polifonik ve kompozisyon özelliklerinin öğretiminde, tematik yapı ve tema takibinin, iki el koordinasyonunun, parti duyurabilme ile müzikal seslendirme vb. gibi önceden edinilmiş becerilerin geliştirilmesinde, analiz yaparak eser çalışma alışkanlığının kazanılmasında önemli bir eğitim aracı olduğu daha önce yapılan birçok araştırmada ortaya konulmuştur.

Bu araştırmanın konusu ve kapsamı gereği, tarama tekniğinden yararlanılmış, örneklem olarak seçilen eserin müziksel ve eğitsel açıdan analizleri yapılarak incelenmiştir. Çalışma sonunda bu ve albümdeki diğer eserlerin öğretme öğrenme sürecinde izlenecek yöntemlere ilişkin öneriler oluşturulmuştur.
\end{abstract}

Anahtar Kelimeler: J. S. Bach, Prelüd ve Füg, Müziksel Analiz, Piyano Eğitimi.

\begin{abstract}
In this study, "The Well-Tempered Claviers: 48 Preludes and Fugues" named piece of Johann Sebastian Bach (1685-1750) was chosen to define the relevance of the piece to educational objectives. The aim was to perform musical analysis and propound the educational properties of $F$ minor BWV No.881 Prelude and Fugue from the piece in terms of piano education.

From a general view, , "The Well-Tempered Claviers: 48 Preludes and Fugues" is accepted as one of the fundamental pieces of piano literature due to the piece being composed for educational purposes, containing the property of prelude and fugue forms, and also being approached as a technical masterpiece.

"The Well-Tempered Claviers: 48 Preludes and Fugues" was used for the teaching of Baroque music's stylistic, polyphonic and composition properties. Many studies have shown that this piece is a very important educational tool for gaining the habit of playing pieces by analyzing and for the improvement of previously earned skills such as thematic structure and theme-following, two-hand coordination, separate announcement of melodies, musical vocalization, etc.

Due to the topic and the scope of this study, descriptive method was used to investigate the chosen pieces as examples by analyzing musically and educationally. The study was concluded by making

Başvuru tarihi: 12.10.2017 - Kabul tarihi: 20.12. 2017.

* Öğr. Gör., Uludağ Üniversitesi Eğitim Fakültesi Güzel Sanatlar Eğitimi Bölümü, Müzik Eğitimi Ana Bilim Dalı, nilyilmaz@uludag.edu.tr.

** Doç. Dr., Uludağ Üniversitesi Eğitim Fakültesi Güzel Sanatlar Eğitimi Bölümü, Müzik Eğitimi Ana Bilim Dalı, redemir@uludag.edu.tr.
\end{abstract}


proposals about methods to be followed during teaching-learning process of the preludes and fugues contained in the above mentioned piece.

Keywords: J.S. Bach, Prelude and Fugue, Musical Analysis, Piano Education.

\section{Giriş}

Türkiye'de mesleki müzik eğitimi veriler kurumlardaki piyano eğitiminde klasik batı müziğinin her dönemine ait eserlere yer verilmektedir. Öğrencilerden bu sanatsal dönemlerin stil özelliklerini yansıtan piyano eserlerini seslendirmeleri ve tanımaları beklenmektedir. Bu sanatsal dönemlerin en önemlilerinden biri de 1600-1750 yıllarını kapsayan Barok dönemidir.

Müziğin oldukça dinamik bir gelişim gösterdiği, Barok olarak nitelendirilen ve 150 yıllık bir süreye egemen olan bu dönem, alabildiğine zengin, renkli ve olağanüstü anlamlı bir yaratış türünün meydana gelmesine imkân sağlamıştır. Müzik sanatında çoğunlukla Polifonik (Polyphonique) [çoksesli] stile yön veren bu dönem, müzik tarihinde Ön-Klasikler Dönemi (Pré-Classique'ler) ya da Bas-Şifre-Çağı (Bas-Chiffré) olarak da adlandırılmaktadır (Altar, 1993:12).

Müzikte Barok çağın başardığı ileriye yönelik başlıca dönüşümlerden biri; modal sistemden tonal sisteme doğru geçiş ve bu geçişin sonucunda müzik tarihinde çok önemli bir aşamaya gelinmesidir. Bu dönemde tonal dizge içinde hareket yeteneği artmış, sistemin standartlaşması ve ton değiştirmeye ilişkin tekniklerin yerleşmesiyle, armoni dünyasının zengin duygusal, dramatik ifade yollarının kapıları açılmıştır (Say, 2002:62).

Johann Sebastian Bach, Alman müziğinin en büyük temsilcisi olup, Barok müziğin ve piyano edebiyatının vazgeçilmez ismidir. Bach'ın ses aralıklarını eşitleyerek dengelemesi (tampere dizi), bugünkü piyano ile birlikte, ezgiye değişik seslerle, uyumlu bir biçimde eşlik etme olanağını yarattığı gibi, birbirinden tamamen ayrı iki çok seslendirme tekniğini, "yatay bir yazı sistemi" olan kontrpuanla, "dikey bir yazı sistemi" olan armoniyi aynı kolaylıkla kullanması üzerinde araştırmalara da olanak sağlamıştır (Kaya, 2009:44).

J.S. Bach'ın yapıtları ise BWV (Bach Werke- Verzeichnis yani Bach eserler dizini) numaraları ile derlenmiştir. Tematik ve sistematik bir düzenleme ile toplanan yapıtların listesi Wolfgang Schmieder tarafından 1950'de basılmıştır. Bu eserler, edition olarak Czerny, Bartok, Kroll, Busoni, Urtext ve Mugellini gibi müzik yayın evleri tarafından yayımlanmıştır. 
Piyano eğitiminde Bach'ın eserleri için en sık kullanılan ve tavsiye edilen Mugellini editörlüğünde yayınlanan notalardır. Bu edisyonun tercih edilmesinin en büyük nedeni eserlerde anlatım terimlerinin bulunması, temaların ve nüansların belirtilmiş olmasıdır. Ayrıca parmak numaralarının yazıımış olması ve notaların hangi elde çalındığının belirtilmesi öğrenci için büyük kolaylık sağlamaktadır.

J. S. Bach'ın "48 Praludien und Fugen für das Wohltemperierte Klavier" (İyi Düzenlenmiş Klavye için 48 Prelüd ve Füg) adı altında iki albümde topladığı eserlerinin her biri, kromatik düzen içinde yarım ton aralıklarla tüm majör ve minör tonlarda yazılmıştır.

Bestecinin, ilk 24 Prelüd ve Füg'ün başına koymuş olduğu açıklama çok belirleyici bir özelliktedir: "Genç müzisyenler için eğitici amaçla bestelenmiş, yarım ses aralıklarla tüm majör ve minör tonlarda yazılmış Prelüd ve Fügler" (Milşteyn, 1967:20).

\subsection{Prelüd, Kontrpuan ve Füg Formunun Biçim Bilgisi}

1.1.1. Prelüd: Genel olarak bir solo çalgı tarafından yorumlanması gereken serbest formda küçük bir giriş parçasıdır. Prelüd için Türkçe "önçalım, öndeyi” terimleri önerilmiştir. Prelüd'ün amacı eserin tonalitesini belirlemektir. Genellikle tek bir tema ya da motif üzerine yazılı, tekrar eden kısa ve ritmik bir öğe üzerine kurulmuş bir eserdir (Erdal, 2003:46).

"48 Prelüd ve Füg" deki prelüdler ya geliştirilmiş bir envansiyondur ya da belirli bir yapısı vardır. Fügle aynı tonda olmaktan başka bir ilişkisi bulunmayabilir. Genellikle tam kararda biter; ya da çok kısa ise, ilgili minörde yarım kararla füge bağlanır (Usmanbaş, 1974).

1.1.2. Kontrpuan: Sözcük anlamı "Notaya karşı nota" olan, "Ezgiye karşı ezgi" anlamında kullanılan terim: iki ya da daha fazla melodinin birbirinden bağımsız, armoni bütünlüğü içerisinde, belirli kurallara göre ilerleyerek birliktelik oluşturduğu polifonik müziğin uygulamasında yer alan yöntemdir (Say, 2002:304).

1.1.3. Füg (Lat., İsp., İt. Fuga. Alm. Fuge, İng., Fr. Fugue): Latince "kaçmak" anlamındadır. Genel bir tanımla; karakteristik bir temanın, kanon ve taklitler aracılığıyla kontrapuantal stilde işlenmesiyle oluşturulan biçimdir.

Füg formu, J. S. Bach'ın eserlerinde en üstün, olgun sanatsal düzeyine ulaşmıştır. Barok çağın özelliklerini taşımasına karşın, daha sonraki dönemlerin bestecileri tarafından 
da benimsenerek değerlendirilmiş, ayrıca bestecilik öğretiminin başlıca çalışma alanlarından biri olmuştur (Say, 2002:209).

Klavye için yazılmış fügler 2 sesten 5 sese kadar olabilir ve bu sesler koro partisine benzetilebilir: Soprano (S), Alto (A), Tenor (T) ve Bas (B).

Füg genel olarak üç bölümden oluşur:

Birinci bölüm, temanın her partide sırayla en az bir kez duyurulduğu "sergi (exposition)"dir. Karşı ezgi eşliğinde, tema ve cevabın nöbetleşe duyuldukları girişlerden oluşur. Sergi ya dominantta ya da ilgili tonda güçlü bir kalış ile biter.

Sergide, fügün ses sayısı kadar "giriş" vardır. Örneğin üç sesli fügde çoğu zaman tema- cevap- tema, dört sesli fügde çoğu zaman tema- cevap- tema- cevap olarak partiler birer birer fügün çoksesliliğine katıırlar. Çok kez cevap- tema ya da tema- cevap aralarında bir veya birkaç ölçülük codetta bulunur. Bu codettalar küçük birer köprüdürler. Bu her fügde olmayabilir (Cangal, 2004:198).

İkinci bölüm, "gelişme (development)" bölümüdür.

Bu bölümün en büyük özelliklerinden biri, ara müzikler ile komşu tonalitelere modülasyonlardır. Diğer bir özelliği de, temanın üzerinde yapılan değişiklikler ve temacevap sıkışmalarıdır.

Şekil bakımından yapılan değişikliklerin başında temanın ters hareketleri gelir. İnici aralıklar çıkıcı, çıkııılar da inici olur. Temanın, daha sonraki partilerde gerçek değerlerinin büyütülmüş olarak duyulması genişleme, küçültülmüş olarak duyulması ise küçültme olarak adlandırilır.

Üçüncü bölüm, "dönüş" veya "sonuç" bölümüdür. Tema üzerinde yapılan değişiklikler, sıkışmalar ve modülasyonlar fazlalaşarak, canlılık ve gerginliğin artmasıyla, füg doruk noktasına ulaşır. Ana temanın dominant tonunda duyurulduğu bu son bölümde eserde artık en yüksek noktaya gelinmiş olur (Aktüze, 2010:226). Füg sonunda tema son kez duyurularak CODA' ya geçilir ve bir kadans ile füg sona erer.

Fügün yapısı üç bölümlü şarkı formu ile sonat formunun yapısına benzemektedir. En önemli farklılıkları, diğerlerinde bölüm sonlarında çok keskin kadansların olmasıdır. Bu yüzden füglerde tekrar yoktur (Koray, 1957:32). 
Fügün yapısını oluşturan başlıca öğeler şunlardır:

- Konu, ana tema, öncü (Lat. Dux, Fr. Sujet, Alm.Subjeckt, It. Proposta)

Fügün çekirdeğini oluşturan ezgidir. Kendine özgü ezgisel ve tartımsal görünümü içinde olan tema, tam bir cümleden ya da bir dönemden oluşan melodik bir olgudur. Tek ölçüden, sekiz ölçüye kadar olabilir. İlk dinleyişte anlaşılır ve akılda kalır bir özelliği vardır. Tonun 1., 3., ve 5. seslerinden başlayabilir ve çok kez ses alanı bir oktavı geçmez. Aynı şekilde tonalitenin 1., 3. veya 5 . sesinde biter.

Tema hangi partide olursa olsun, her zaman aynı karakterde ve ritimde çalınır. Sadece nüanslar farklı olabilir.

- Cevap (Lat. Comes, It.Riposta, Fr.Reponse)

Fügün başlangıcında "tema" tek başına kendini duyurduktan sonra, ardından "cevap" başka bir partide dominant tonunda duyulur. Genelde "tema" biter bitmez "cevap" başlar. "Cevap" "tema"nın aktarılmış halidir. "Tema"yı oluşturan sesler arasındaki ilişkiye göre, "cevap" ta gelen ezgide birebir aktarım yapılmadığı, bazı seslerin (aralıkların) ezgisel yönü aynı olmakla beraber değişikliğe uğradığı görülür. Bu durumda "Cevap", "Tema” yı dominant tonalitesinde bazı değişikliklere uğrayarak taklit etmişse "Tonal Füg", hiç değişikliğe uğramadan taklit etmişse "Real Füg” (Gerçek Füg) denir (Devrim, 2007:13).

- Karşı tema, karşı ezgi (Alm. Kontarpunkt, Fr. Contrepoint, İt. Controsoggetto)

Tema, cevabın duyulduğu andan itibaren ezgisel yoluna devam ederek cevabı bir karşı tema, karşı ezgi ile örer. İkili kontrpuan şeklinde yazılmış, tema ve cevabı tamamlayan, temanın öteki partilerdeki her girişinde ona eşlik eden bir ezgidir.

Temanın iyi bir devamı olan karşı ezgi, ezgisel ve tartımsal yönü ile cevaptan ayrı olmasına karşın, cevap ile gizlice kaynaşarak bir bütünlüğe ulaşır, onu zenginleştirir, onun belirgin olmasını sağlar ve hiçbir zaman onu örtmez (Cangal, 2004:194).

- Ara müzik (Fr. Divertissement, Ing. Episode); ara kısım, ara çalın, oyalama.

Tema ve cevaplar arasında bağlantıyı sağlayan küçük ezgisel gidişler vardır. Bir fügün bölümleri arasındaki ara müzikleri, genellikle tema veya karşı ezgi parçacıkları üzerine kurulmuş tonalite değişimli (modülasyonlu) köprülerdir (Cangal, 2004:200). Ara müziklerin asıl amacı, tema girişleri arasında bir rahatlama yaratmak ve bir sonraki tema girişini hazırlamaktadır. 


\section{Yöntem}

$\mathrm{Bu}$ araştırmanın konusu ve kapsamı gereği, tarama tekniğinden yararlanılmış, örneklem olarak J. S. Bach'ın “ìi Düzenlenmiş Klavye İçin 48 Prelüd ve Füg” adlı eserinden Fa Minör BWV 881 Prelüd Ve Füg'ün bölümleri ayrıştırılarak ayrıntılı form analizi yapılmıştır. Çalışmada örneklem olarak seçilen bu eserin öğretme- öğrenme sürecinde izlenecek yöntemlere ilişkin öneriler, yapılan müziksel analiz üzerinden yola çıkarak geliştirilmiştir.

\section{Bulgular ve Yorum}

Bu bölümde J. S. Bach’ın “ìyi Düzenlenmiş Klavye İçin 48 Prelüd ve Füg” adlı eserin 2. Albüm'de bulunan No12 BWV 881 Fa Minör Prelüd ve Füg'ün müziksel analizine yer verilmiştir.

\subsection{Prelüd}

Polifonik stilde Bach'ın yazmış olduğu bu prelüd teknik açıdan "48 Prelüd ve Füg”ün en kolay prelüdlerinden biridir. Andante mosso temposunda olup, hüzünlü atmosfere sahip olmasına rağmen prelüd ağır tempolu bir eser olarak düşünülmemelidir. Prelüd form açısından üç bölümden oluşur (Bkz Görsel 1,2 ve 3). Ancak daha detaylı incelendiğinde Fa Minör Prelüd'ün geliştirilmiş bir sonat formunda yazıldığı görülmektedir.

Birinci Bölüm: Sergi

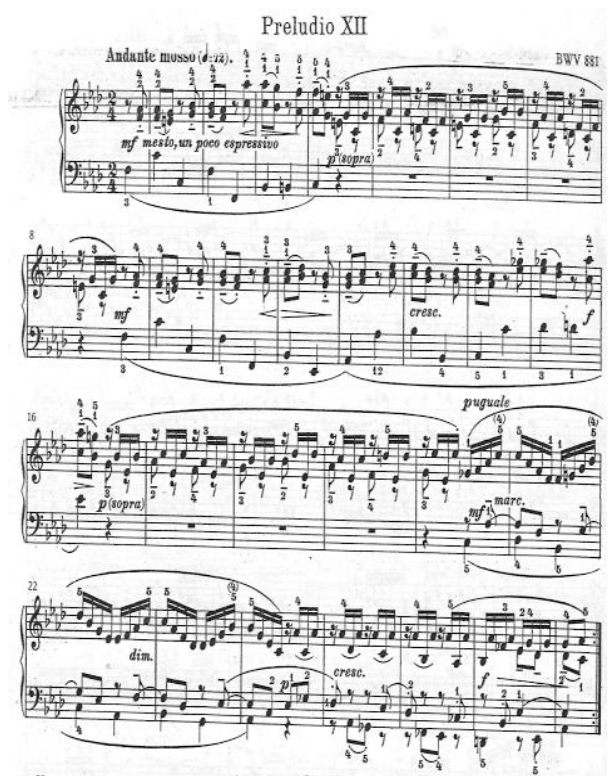

Görsel 1. J. S. Bach’ın “iyi Düzenlenmiş Klavye İçin 48 Prelüd ve Füg" 2. Albüm No 12 Fa Minör BWV 881 Prelüd 1- 28. ölçünün ilk yarısı (B. Mugellini Edition, Breikopf 2375, 1964).

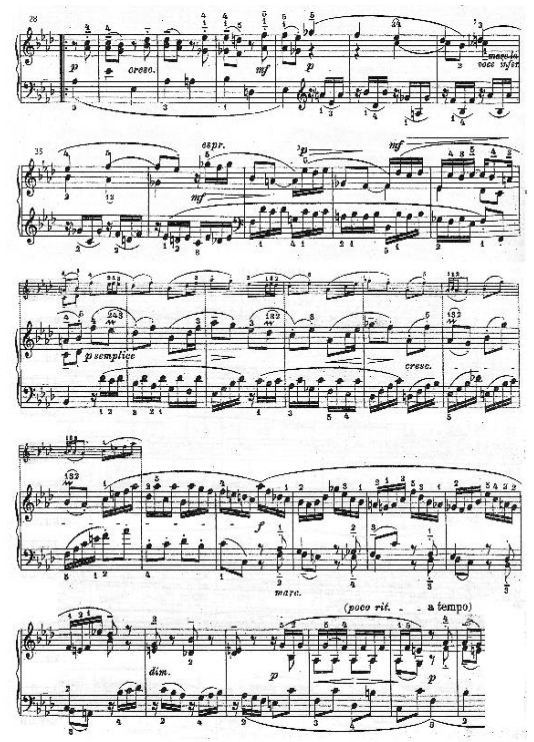

Görsel 2. J. S. Bach'ın “iyi Düzenlenmiş Klavye Için 48 Prelüd ve Füg" 2. Albüm No 12 Fa Minör BWV 881 Prelüd 28. ölçünün ikinci yarısı - 56. ölçünün ilk yarısı (B. Mugellini Edition, Breikopf 2375, 1964 
ìkinci Bölüm: Gelişme

Üçüncü Bölüm: Kısaltılmış yeniden Sergi
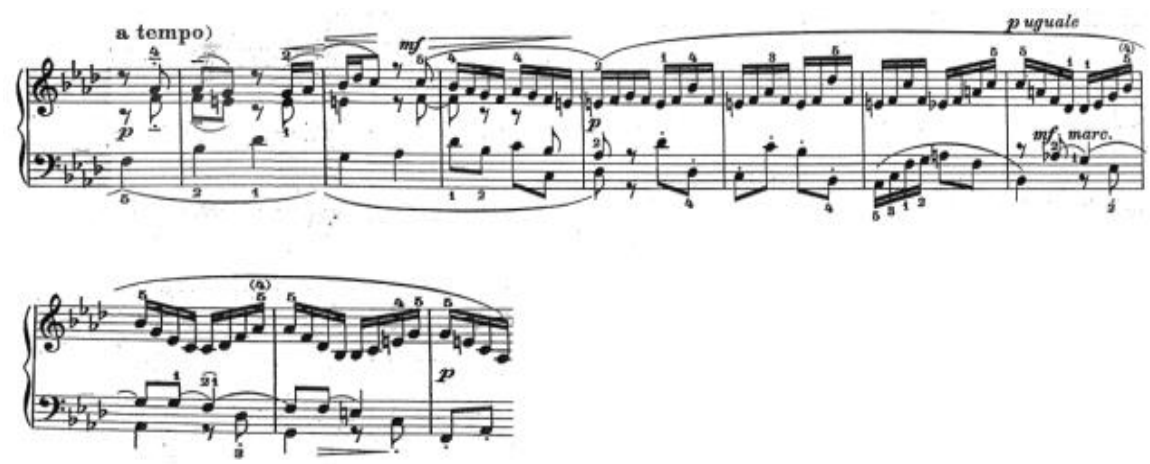

Görsel 3. J. S. Bach'ın “iyi Düzenlenmiş Klavye iç̧in 48 Prelüd ve Füg” 2. Albüm No12 Fa Minör BWV 881 Prelüd 56. ölçünün ikinci yarısı- 66. ölçünün birinci yarısı (B. Mugellini Edition, Breikopf 2375, 1964).

Prelüd'teki tema ustalıkla kaynaştırılan iki motften oluşur (Bkz Görsel 5 ve 6). Birinci motif ön duyurmalı çift ses sekizlik notalardan oluşan bir motiftir. Müzik tarihçilerinin "iç çekme" motifi olarak adlandırdıkları motif, bölümün tümünde kendini hissettirir.

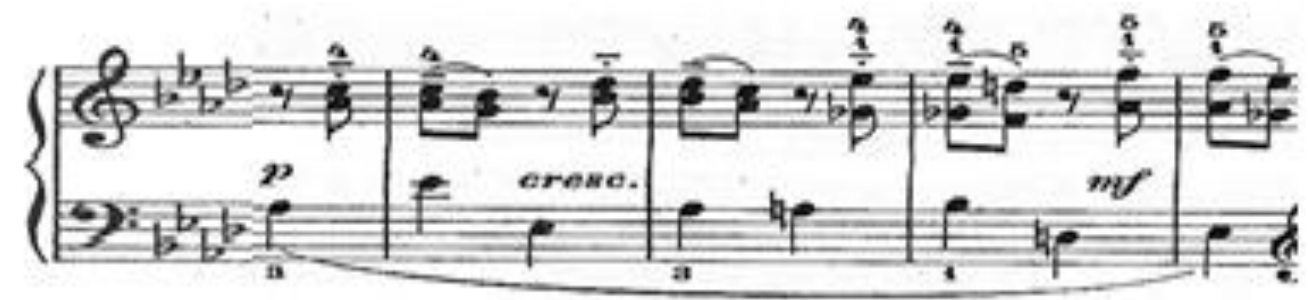

Görsel 4. J. S. Bach'ın “iyi Düzenlenmiş Klavye Iç̧in 48 Prelüd ve Füg” 2. Albüm No12 Fa Minör BWV 881 Prelüd eksik ölçü- 4. ölçünün birinci yarısı (B. Mugellini Edition, Breikopf 2375, 1964).

İkinci motif ise onaltılık notalardan oluşmaktadır.

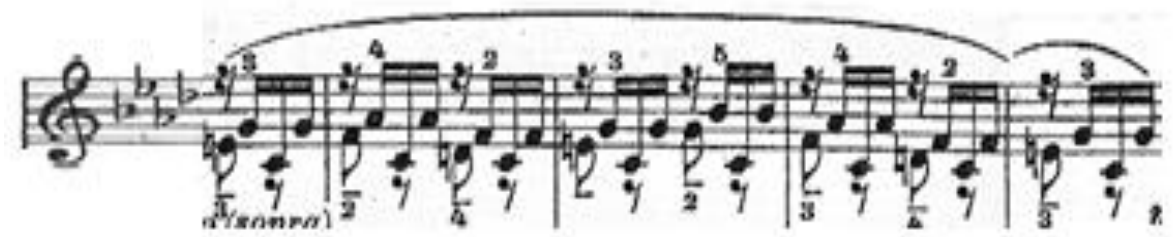

Görsel 5. J. S. Bach’ın “ìi Düzenlenmiş Klavye İçin 48 Prelüd ve Füg” 2. Albüm No12 Fa Minör BWV 881 Prelüd 4. ölçünün ikinci yarısı- 8. ölçünün birinci yarısı (B. Mugellini Edition, Breikopf 2375, 1964).

Seslendirme aşamasında prelüd temadaki çift seslerin zayıf zamandaki sekizlikler staccato, diğerleri güçlü zamanda legato çalınmalıdır. İkinci motif ve benzeri pasajlardaki 
sekizlikleri diğer partideki onaltılıklar ile tek bir melodik çizgi oluşturmaları açısından özellikle kısa çalmak anlamlıdır (Bodki, 1993:119).

Bu iki motif duyurulduktan sonra farklı bir ezgi de eklenerek paralel tonaliteye (la bemol majör) doğru modülasyon yapılır ve ikinci bölüm (gelişme) hazırlanır.

Gelişme bölümünde 1. motif duyulduktan sonra

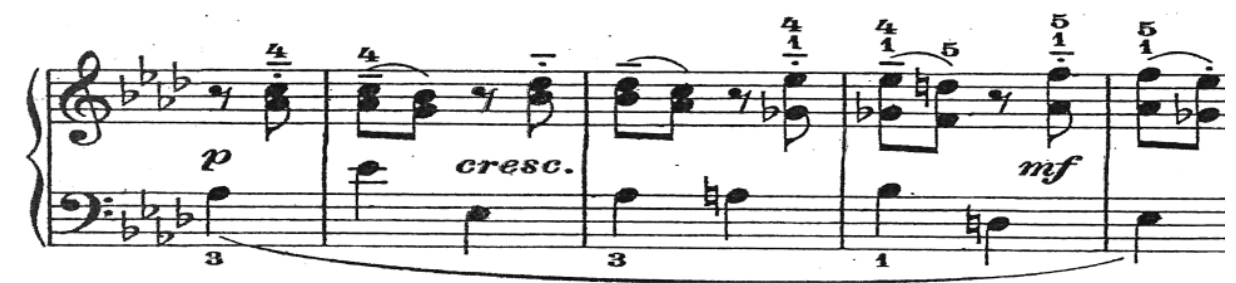

Görsel 6. J. S. Bach'ın “iyi Düzenlenmiş Klavye iç̧in 48 Prelüd ve Füg” 2. Albüm No12 Fa Minör BWV 881 Prelüd 28. ölçünün ikinci yarısı- 32. ölçünün birinci yarısı (B. Mugellini Edition, Breikopf 2375, 1964).

2. motif bir cevap şeklinde 1. motifin devamına yerleşir.

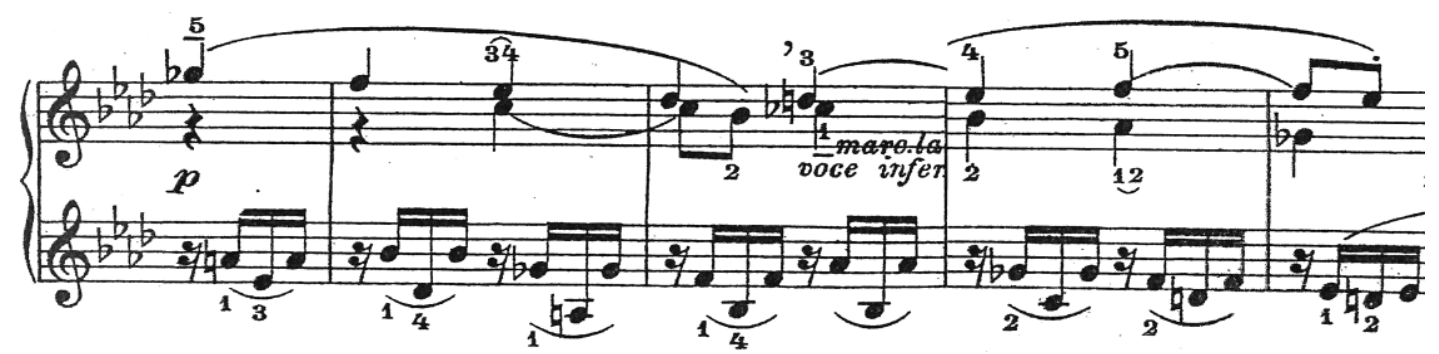

Görsel 7. J. S. Bach'ın “lyi Düzenlenmiş Klavye Iç̧in 48 Prelüd ve Füg” 2. Albüm No12 Fa Minör BWV 881 Prelüd 32. ölçünün ikinci yarısı- 36. ölçünün birinci yarısı (B. Mugellini Edition, Breikopf 2375, 1964).

Devamında 2. motif daha serbest bir şekilde kullanılmıştır.

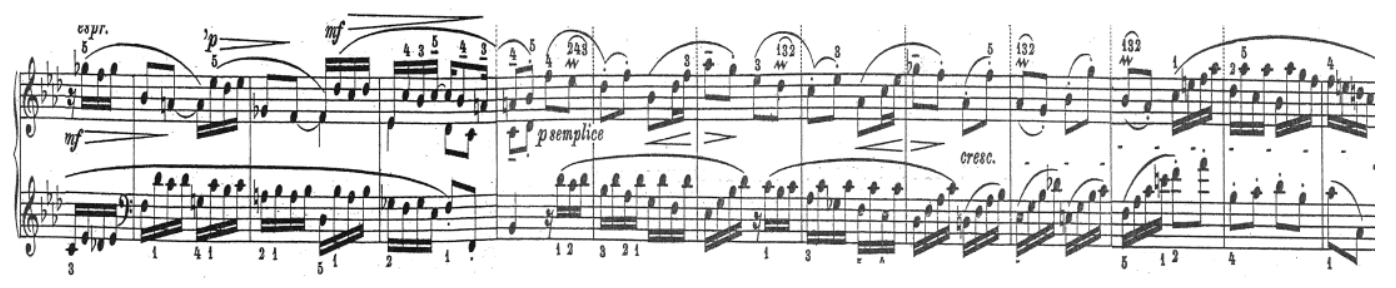

Görsel 8. J. S. Bach'ın “iyi Düzenlenmiş Klavye için 48 Prelüd ve Füg” 2. Albüm No12 Fa Minör BWV 881 Prelüd 36. ölçünün ikinci yarısı- 48. ölçünün birinci yarısı (B. Mugellini Edition, Breikopf 2375, 1964)

Gelişme bölümünün son sekiz ölçüsü ile sergi bölümünün son sekiz ölçüsü benzerlik göstermektedir. Aynı benzerlik Yeniden Sergi bölümünün sonunda da gözlenmektedir. (Bkz. Görsel 10,11 ve 12). 


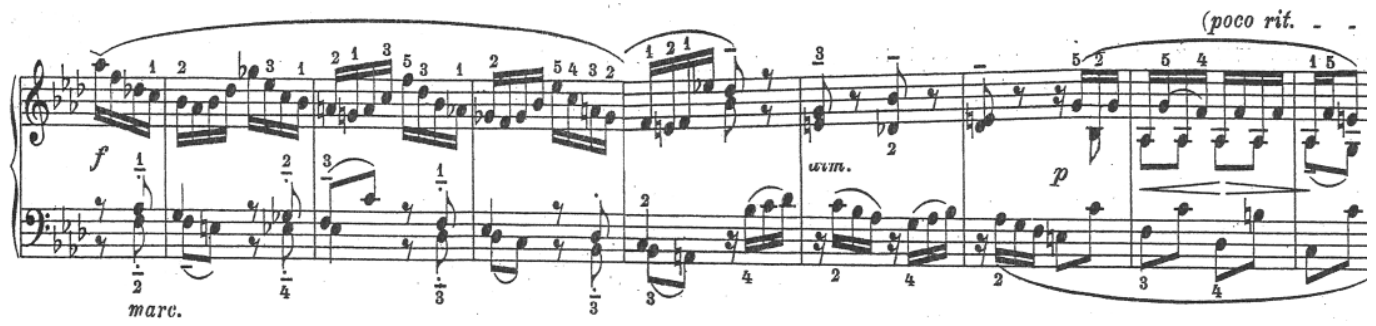

Görsel 9. J. S. Bach'ın “iyi Düzenlenmiş Klavye iç̧in 48 Prelüd ve Füg” 2. Albüm No12 Fa Minör BWV 881 Prelüd 48. ölçünün ikinci yarısı- 56. ölçünün birinci yarısı (B. Mugellini Edition, Breikopf 2375,1964).

Sergi bölümündeki ezgi

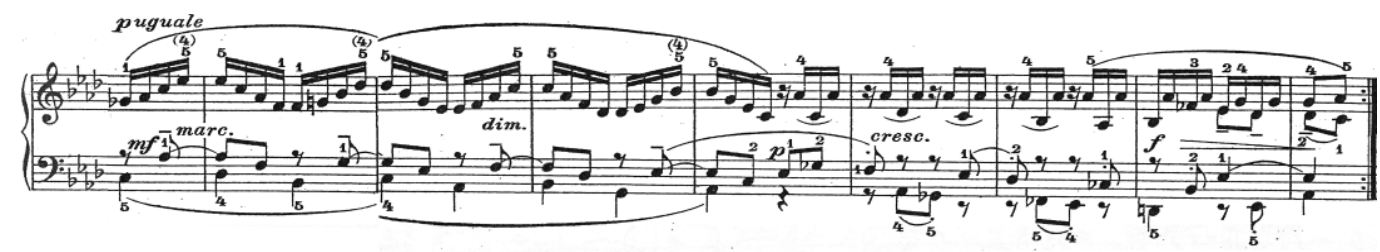

Görsel 10. J. S. Bach'ın “ijyi Düzenlenmiş Klavye Iç̧in 48 Prelüd ve Füg” 2. Albüm No12 Fa Minör BWV 881 Prelüd 20. ölçünün ikinci yarısı- 28. ölçünün birinci yarısı (B. Mugellini Edition, Breikopf 2375, 1964).

Yeniden Sergi bölümündeki ezgi

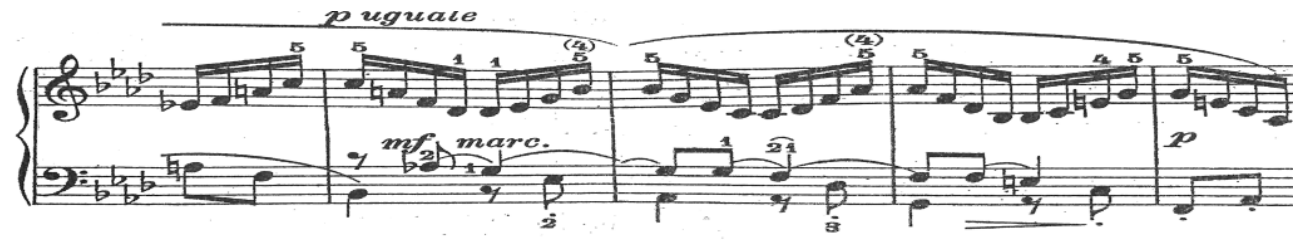

Görsel 11. J. S. Bach'ın “ilyi Düzenlenmiş Klavye Içcin 48 Prelüd ve Füg” 2. Albüm No12 Fa Minör BWV 881 Prelüd 62. ölçünün ikinci yarısı- 66. ölçünün birinci yarısı (B. Mugellini Editio Breikopf 2375, 1964).

Motiflerin işlenmesi, benzeri ve farklı ezgilerden oluşan gelişme bölümü ana tonalitenin (fa minör) beşinci derece (do majör) tonalitesinde poco rit. yapılarak biter. Hemen ardından gelen yeniden sergi bölümü ana tonalitede başlar. CODA ana tonalitenin dördüncü derece akoruna doğru modülasyon yaparak duraklar ve kırık kadans ile eser sakin bir şekilde biter (Bkz. Görsel 12). 


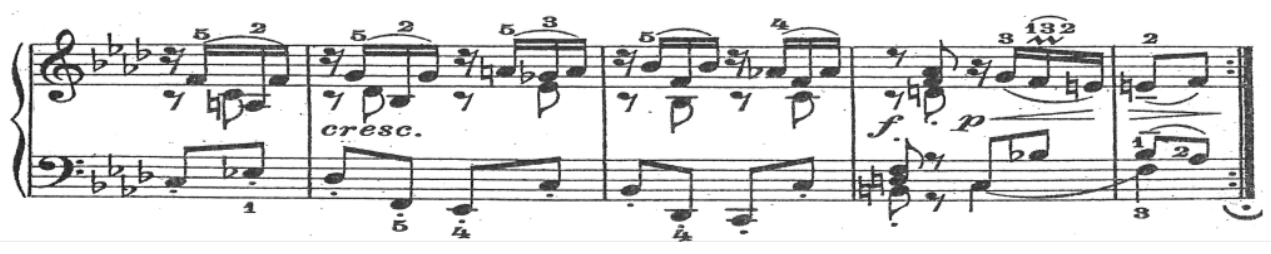

Görsel 12. J. S. Bach'ın “ijyi Düzenlenmiş Klavye İçin 48 Prelüd ve Füg” 2. Albüm No12 Fa Minör BWV 881 Prelüd 66. ölçünün ikinci yarısı- 70. ölçünün birinci yarısı (B. Mugellini Editio Breikopf 2375, 1964).

\section{2. Üç Sesli Füg (tonal)}

Fa minör Füg, prelüdü gibi 48 Prelüd- Füg”ün 2. Albüm'deki en kolay anlaşılabilen füglerdendir. Füg oldukça serbest bir formda yazıımıştır.

Birinci bölüm - Sergi
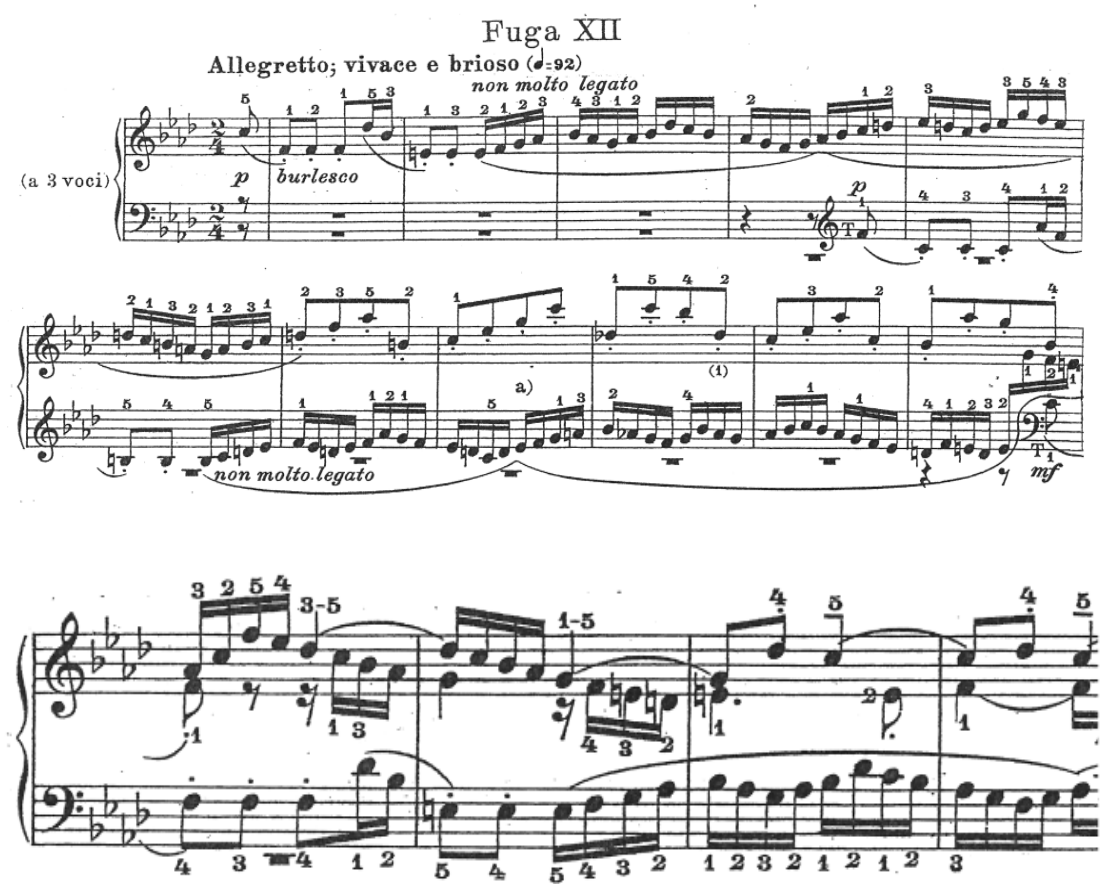

Görsel 13. J. S. Bach’ın “ìi Düzenlenmiş Klavye Içcin 48 Prelüd ve Füg” 2. Albüm No12 Fa Minör BWV 881 Füg eksik ölçü- 15. ölçünün birinci yarısı (B. Mugellini Edition, Breikopf 2375, 1964).

Sergi bölümü tema- cevap -codetta- tema şeklindedir (Bkz Görsel 14, 15, 16 ve 17)

Tema

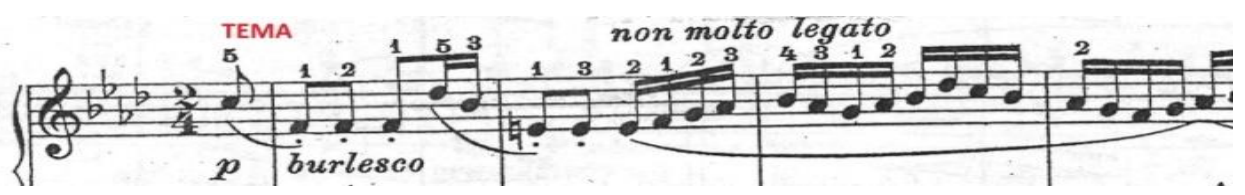

Görsel 14. J. S. Bach'ın “ìi Düzenlenmiş Klavye İçin 48 Prelüd ve Füg” 2. Albüm No12 Fa Minör BWV 881 Füg eksik ölçü- 4. ölçünün birinci yarısı (B. Mugellini Edition, Breikopf 2375, 1964). 
Bu fügdeki tema, ezgi yönünden zengin olup, sekizlik nota değeri, eksik ölçü ile sopranoda başlar. Seslendirme aşamasında birinci vuruşun belirtilmesi gerekmektedir. Dört ölçülüktür ve ana tonalitenin beşlisi ile başlayıp üçlüsü ile biter.

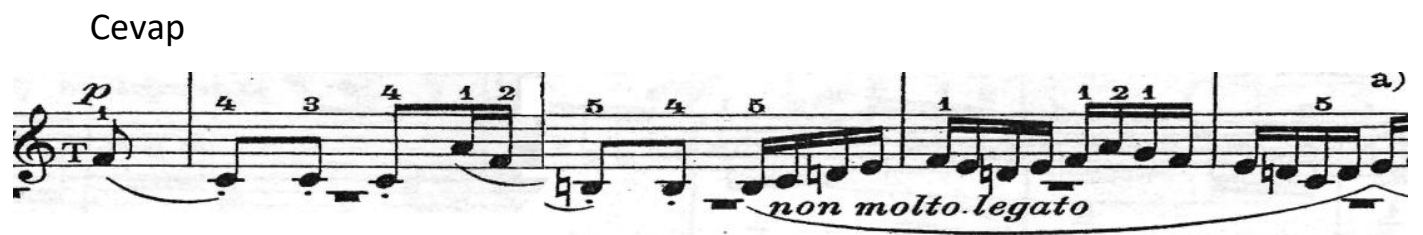

Görsel 15. J. S. Bach'ın “ìi Düzenlenmiş Klavye İçin 48 Prelüd ve Füg” 2. Albüm No12 Fa Minör BWV 881 Füg 4. ölçünün son sekizliği- 8. ölçünün birinci yarısı (B. Mugellini Edition, Breikopf 2375,1964).

Tema biter bitmez cevap orta partide (alto) sol elde başlar. Temanın beşinci derece tonalitesine (do minör) aktarılmış halidir. Ezgisel yönü aynıdır. Ancak aralıklar farklı olduğu için füg'ün tonal füg olduğu söylenebilir.

Karşı Tema

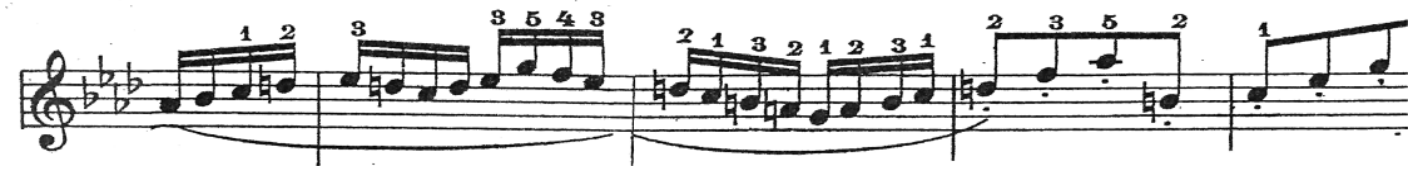

Görsel 16. J. S. Bach'ın “ìi Düzenlenmiş Klavye için 48 Prelüd ve Füg” 2. Albüm No12 Fa Minör BWV 881 Füg 4. ölçünün son sekizliği- 8. ölçünün birinci yarısı (B. Mugellini Edition, Breikopf 2375, 1964).

Karşı tema, temanın devamı gibidir. Onaltılıklar ile bir bütünlüğe ulaşır, zenginleştirir ve cevabın belirgin olmasını sağlar. Ikili kontrpuan şeklindedir.

Sergi bölümünde cevap ile tekrar tema arasında kısa bir codetta bulunur.

\section{Codetta}

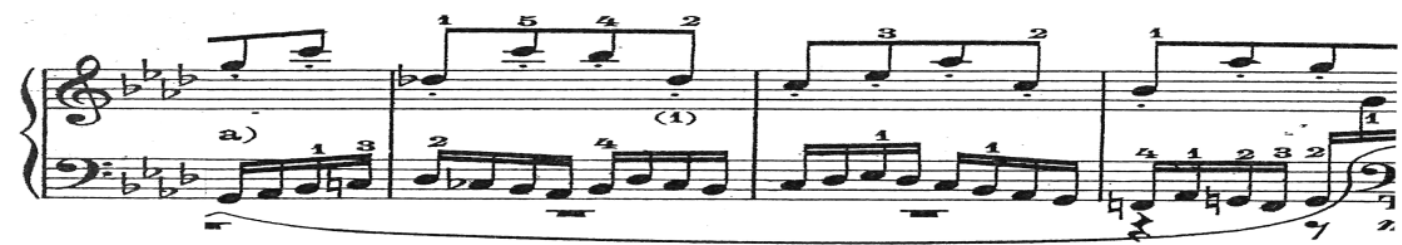

Görsel 17. J. S. Bach’ın “íi Düzenlenmiş Klavye Için 48 Prelüd ve Füg” 2. Albüm No12 Fa Minör BWV 881 Füg 6. ölçünün ikinci yarısı- 9. ölçünün ikinci yarısı (B. Mugellini Edition, Breikopf 2375,1964).

Codetta' nın görevi cevap ile temayı kaynaştırmaktır. Codetta'dan sonra bas sesinde tekrar ana tondaki temaya dönülür. 
Birinci bölümde (sergi, exposition) temalar bütün seslerde duyurulduktan sonra sergi biter ve ara müzik ile paralel tonaliteye (la bemol majör) doğru modülasyon yaparak ikinci bölümü (gelişme) hazırlar.

- Birinci Ara Müzik

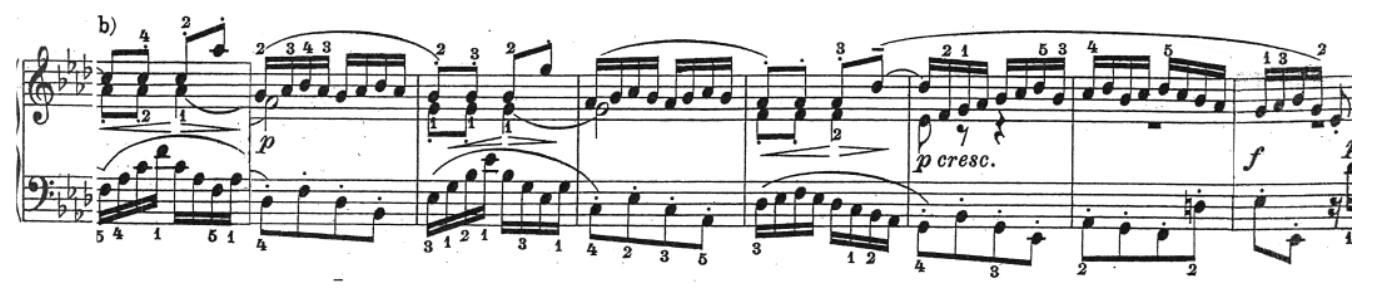

Görsel 18. J. S. Bach’ın “ìi Düzenlenmiş Klavye Için 48 Prelüd ve Füg” 2. Albüm No12 Fa Minör BWV 881 Füg 15. ölçünün ikinci yarısı- 24. ölçünün ikinci yarısı (B. Mugellini Edition, Breikopf 2375,1964).

İkinci Bölüm- Gelişme

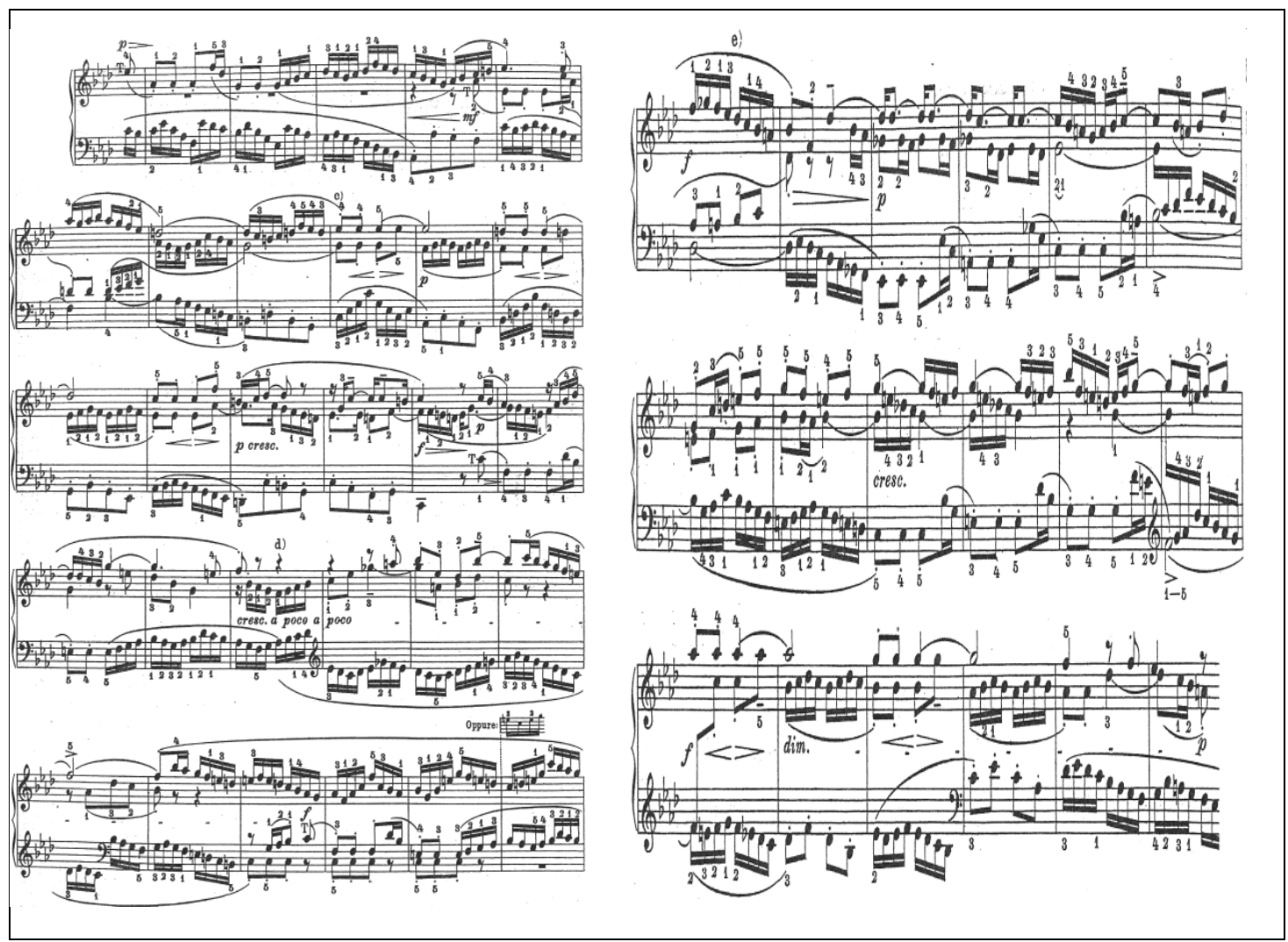

Görsel 19. J. S. Bach’ın “ìi Düzenlenmiş Klavye İçin 48 Prelüd ve Füg” 2. Albüm No12 Fa Minör BWV 881 Füg 24. ölçünün son sekizliği- 71. ölçünün ikinci yarısı (B. Mugellini Edition, Breikopf 2375, 1964).

Paralel tonalitede (la bemol majör) temanın duyurulmasıyla gelişme bölümü başlar. La bemol majör tonalitenin beşinci derece tonalitesinde (mi bemol majör) cevap verildikten sonra, yine ara müzikler ile ana tonalitenin (fa minör) dördüncü derece tonalitesine (si bemol minör) doğru modülasyon yapılır. 
Gelişme Bölümünde Ara Müzikler

ikinci Ara Müzik

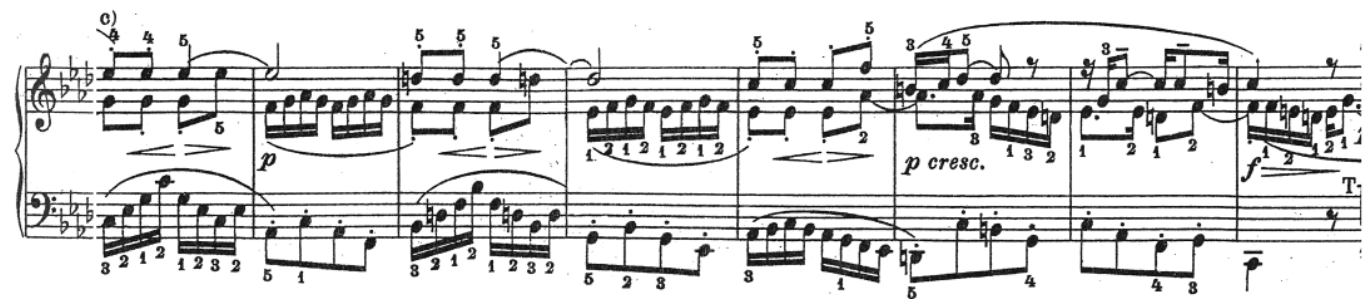

Görsel 20. J. S. Bach’ın “iyi Düzenlenmiş Klavye Için 48 Prelüd ve Füg” 2. Albüm No12 Fa Minör BWV 881 Füg 32. ölçünün ikinci yarısı- 40. ölçünün birinci yarııı (B. Mugellini Edition, Breikopf 2375,1964).

Üçüncü Ara Müzik

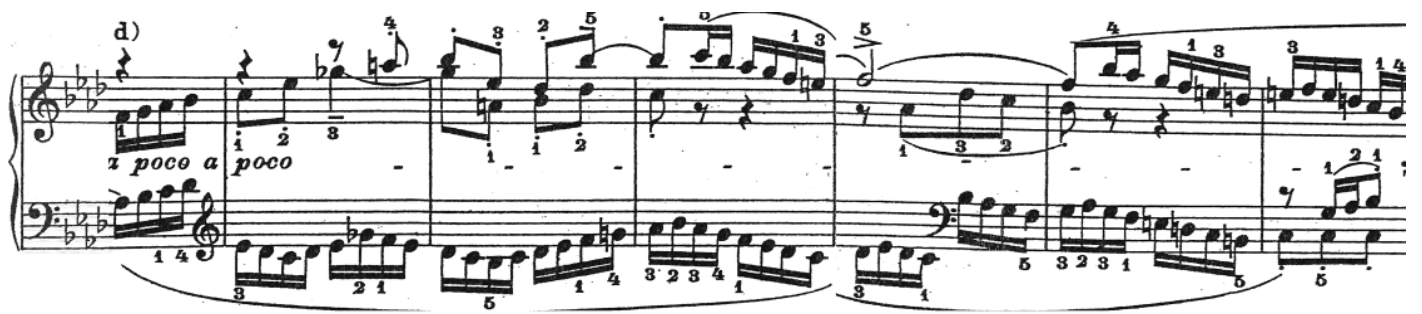

Görsel 21. J. S. Bach'ın “iyi Düzenlenmiş Klavye için 48 Prelüd ve Füg” 2. Albüm No12 Fa Minör BWV 881 Füg 44. ölçünün ikinci yarısı- 50. ölçünün ikinci yarısı (B. Mugellini Edition, Breikopf 2375,1964).

Dördüncü Ara Müzik

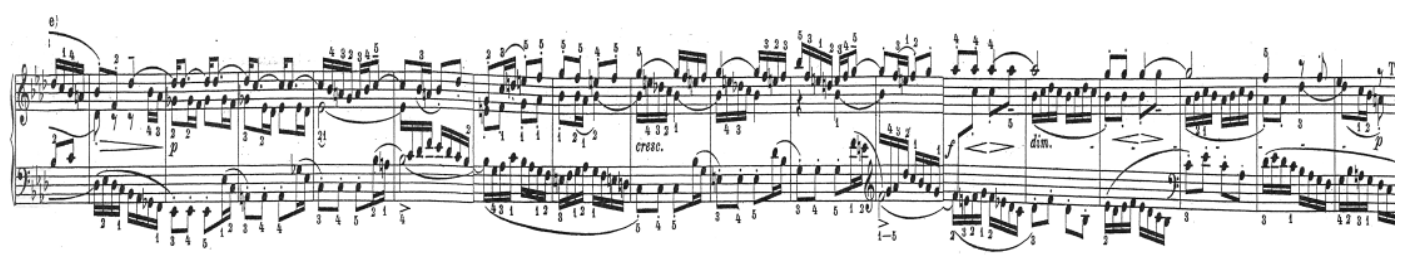

Görsel 22. J. S. Bach’ın “ijyi Düzenlenmiş Klavye Için 48 Prelüd ve Füg” 2. Albüm No12 Fa Minör BWV 881 Füg 54. ölçünün ikinci yarısı- 71. ölçünün birinci yarısı (B. Mugellini Edition Breikopf 2375,1964).

Üçüncü Bölüm- Sonuç

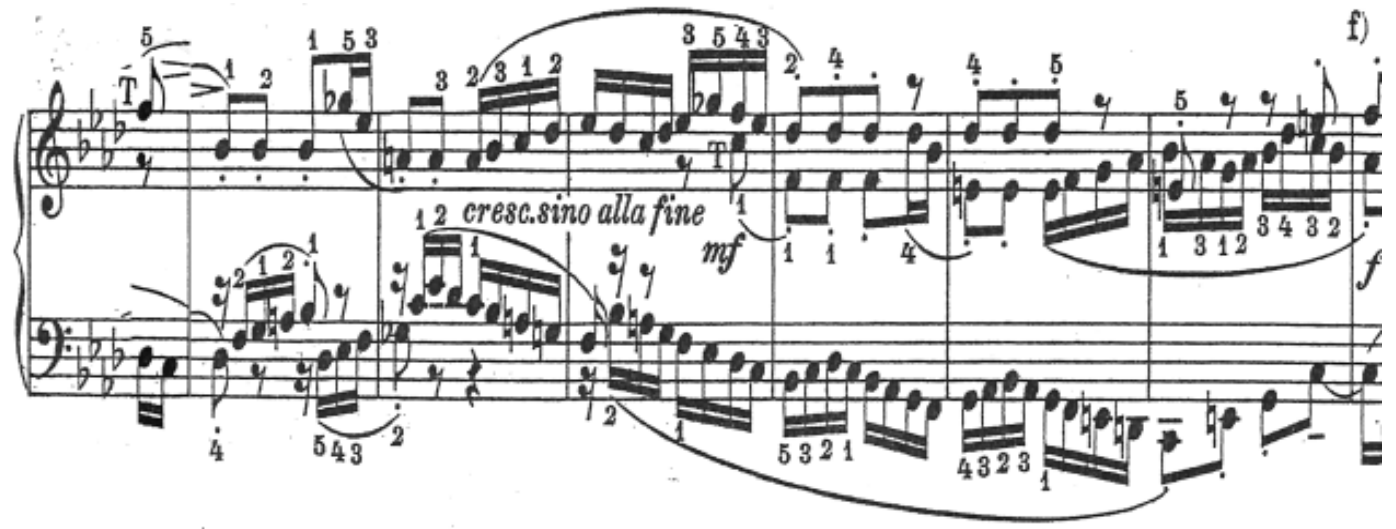

Görsel 23. J. S. Bach'ın “iyi Düzenlenmiş Klavye için 48 Prelüd ve Füg” 2. Albüm No12 Fa Minör BWV 881 Füg 71. ölçünün ikinci yarısı- 78. ölçünün ilk sekizliği (B. Mugellini Edition, Breikopf 2375,1964). 
Ana tonalitenin dördüncü derece (si minör) tonalitesinde duyulan tema ile üçüncü bölüm (sonuç) başlar. Cevap da si minör tonalitenin beşinci derece (fa minör) tonalitesinde olunca ana tonaliteye dönülmüş olur.

Coda

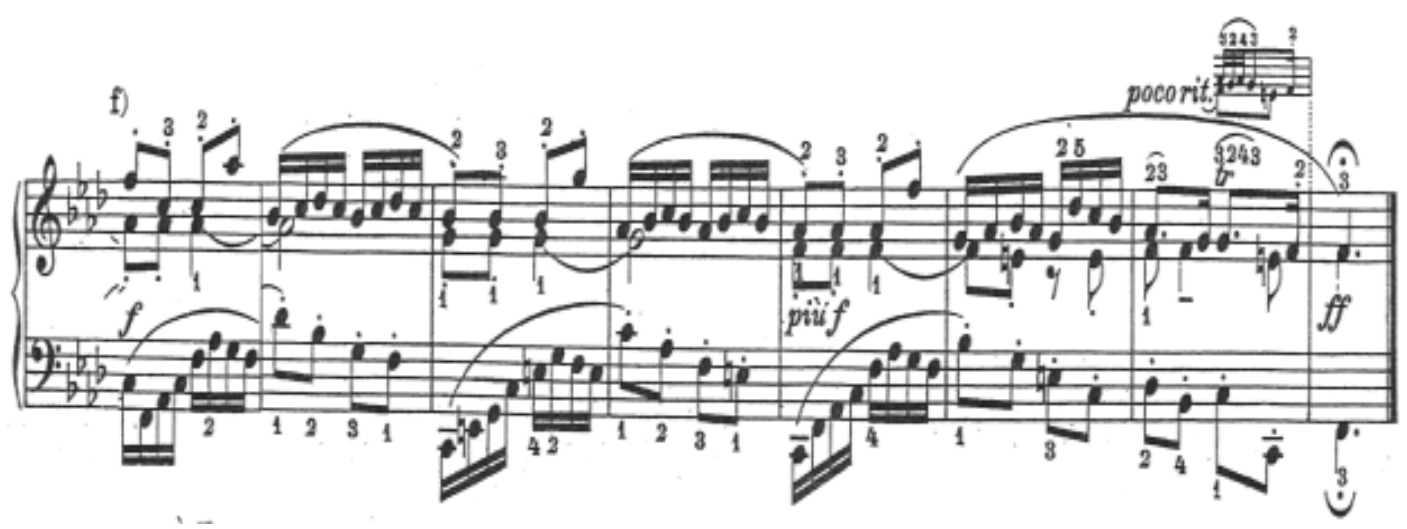

Görsel 24. J. S. Bach’ın “iyi Düzenlenmiş Klavye Için 48 Prelüd ve Füg” 2. Albüm No12 Fa Minör BWV 881 Füg 78. ölçü - füg sonuna kadar (B. Mugellini Edition, Breikopf 2375,1964).

Fügün sonu bir Coda ile hazırlanır ve yapılan kadans ile karara varılarak füg sona erer. Kontrpuantal anlamda yalın bir yazıya sahip bu fügde temanın canlı girişiyle başlayan hareketli karakter, parçanın son ölçüsüne kadar sürekli bir şekilde devam eder.

\section{Sonuç}

J. S. Bach’ın "iyi Düzenlenmiş Klavye İçin 48 Prelüd ve Füg" adlı eserinin eğitsel amaçlarla yazıımış olması, prelüd ve füg formunda mükemmel bir nitelik taşıması, ayrıca piyano eğitiminde kullanılan teknik bir başyapıt olarak ele alınıyor olması gibi nedenlerle, piyano literatürünün temel yapı taşlarından biri olduğu kabul edilmektedir. "İyi Düzenlenmiş Klavye İçin 48 Prelüd ve Füg" barok müziğin stilistik, polifonik ve kompozisyon özelliklerinin öğretiminde, tematik yapı ve tema takibinin, iki el koordinasyonunun, parti duyurabilme ile müzikal seslendirme vb. gibi önceden edinilmiş becerilerin geliştirilmesinde, analiz yaparak eser çalışma alışkanlığının kazanılmasında önemli bir eğitim aracı olduğu yaygın olarak kabul görmektedir.

Piyano eğitiminde kazandırılmak istenilen davranışlara göre seçilen materyalin öğretilmesinde kullanılacak yöntemlerin belirlenmesi, teorik ön bilgilerin yanında, her eğitimci için sürece dayalı biçimde oluşup gelişen bir birikim gerektirmektedir. 
J.S. Bach'ın," 48 Prelüd ve Füg" leri piyano eğitiminde hedeflenen birçok becerinin kazandırımasında aynı zamanda etkili bir eğitici materyal niteliği taşımaktadır. Bu eserler Eskioğlu (2003)' nun da belirttiği gibi;

- Barok müziğin çok seslilik anlayışının (polifoni) öğretiminde,

- Süslemelerin öğretiminde,

- Kontrpuan tekniklerinin analizinde,

- Tematik yapının takip edilmesinde,

- İki elin koordinasyonunun geliştirilmesinde,

- Tek elde iki veya üç sesli partileri duyurabilme becerisinin geliştirilmesinde,

- Tutan seslerin iyi bir legato tekniğiyle çalınmasının öğretiminde,

- Tuşe hakimiyetinin geliştirilmesinde,

- Aşamalı biçimde konsantrasyonun geliştirilmesinde,

- Şarkı söyler gibi çalabilme tekniğinin kazanılmasında,

- Müziksel anlatımı/düşünceyi geliştirmesinde,

- Eserlerin yapısından dolayı disiplinli çalışma tekniğinin kazandırıımasında,

- Önceden kazanılmış becerilerin geliştirilmesi vb. beceri ve özelliklerin kazandırımasında etkili olabilir.

Piyano eğitimcilerinin ilk kez bu eserlerden birini çalışacak öğrenciler için, öncelikle besteci-tür-form-stil vb. bilgisi vermesi, bu tarza yönelik önceden kazanılan bilgilerin pekiştirilmesini sağlayıcı yöntemlere başvurmasının uygun olduğu söylenebilir.

"48 Prelüd ve Füg” lerin öğretme-öğrenme sürecinde izlenecek yöntemler konusunda aşağıdaki önerilerin uygulanmasının yararlı olabileceği düşünülmektedir:

- Füg'de tema her zaman ön planda olmalıdır.

- Illk duyuluşu ana tonda olan temanın girişi ve sonu önemlidir. Bunun için temaların girişleri T harfiyle ve renkli kalemle notalar üzerinde işaretlenerek belirlenmelidir.

- Eserde geçen tüm temalar tek tek çalınarak karakterlerin ve ritmik özelliklerin aynı olmasına dikkat edilerek, sadece nüanslar değişebilmelidir.

- Temalar armonik açıdan incelenmeli ve değiştiricilere dikkat edilmelidir.

- Notalar üzerinde sergi bölümünün sınırları çizilerek belirtilmelidir. 
- Tema çalışmalarından sonra cevaplar da benzer biçimde işlenmelidir.

- Daha sonra tema ve cevaplar birleştirilmelidir.

- Önce sağ el partisi (2 veya üç ses) temanın duyurulmasına dikkat edilerek çalışımalı ve sonra da sol el aynı şekilde çalınmalıdır.

- Eğer tema bir elden diğer ele geçerek devam ederse, seslerin kopmamasına özen gösterilmelidir.

- Tutan sesler biraz destekli çalınmalıdır.

- Nüanslarda aşırıya kaçılmamalıdır.

- Orta ve son bölümün çalışılmasında da benzer yöntem izlenmelidir.

Uygulanacak bu yöntemlerin J.S. Bach özelinde tüm polifonik eserlerin çalışılmasında rehber olarak izlenebileceği, öğrencilerin titiz bir çalışma ile bu eserlerin önemini daha fazla kavramaları ve faydalanmaları konusunda yararlı olacağı düşünülmektedir.

\section{Kaynakça}

Aktüze, ì. (2010). Müziği Anlamak Ansiklopedik Müzik Sözlüğü, İstanbul: Pan Yayıncılık.

Бодки, Э. “Bodki, Е.” (1993). Интерпретация клавирных произведений И.С.БАХА "Interpretatsiya klavirnıh proizvedeniy i.S. BAHA." (J.S. Bach'ın klavir eserlerinin yorumu), Москва "Moskova”: Издательство Музыка "izdatelstva Muzıka” (Müzik Yayınları).

Cangal, N. (2004). Müzik Formları, Ankara: Arkadaş Yayınevi.

Devrim, S. At, (2007). J. S. Bach 48 Prelüd- Füg, İstanbul: Bu yayınevi.

Erdal, B, (2003). Barok Dönemdeki Türler ve Biçimlerin Biçim Bilgisi Iç̧indeki Yeri ve Biçim Bilgisi Dersinin Gerekliliği, Yayımlanmamış Yüksek Lisans Tezi, İzmir: Dokuz Eylül Üniversitesi, Eğitim Bilimleri Enstitüsü, Güzel Sanatlar Eğitimi Anabilim Dalı.

Eskioğlu, I. (2003). "Johann Sebastian Bach'ın Envansiyonları'nın Piyano Eğitimi Dağarcığındaki Önemi ve Bu Yapıtların Incelenmesi", Müzik Sempozyumu, 30 - 31 Ekim. Malatya: İnönü Üniversitesi.

Kaya, D. (2009). "Johan Sebastian Bach'ın "Füg Formları"nın ve "Füg Sanatı" Adlı Eserinin Barok Dönemi Müzik Anlayışına Göre Incelenmesi", Yayımlanmamış Yüksek Lisans Tezi, Adana: Çukurova Üniversitesi, Sosyal Bilimler Enstitüsü, Müzik Ana Sanat Dalı.

Koray, F. (1957). Müzik Formları, İstanbul: Maarif Basımevi Öğretmen Kitapları, s. 62.

Мильштейн. Я." Milşteyn. Үa" (1967). Хорошо темперированный клавир И. С. БАХА и особенности его исполнения, "Haroşiy temperiravannıy klavir i.S. BAHA i asobennasti evo ispalneniya", ( Bah'ın iyi düzenlenmiş klavye için eserleri ve onların icra özellikleri), Москва “Moskova”: Издательство Музыка, “izdatelstva Muzıka” (Müzik Yayınları). 
Say, A. (2002). Müzik Sözlüğ̈̈, Ankara: Müzik Ansiklopedisi Yayınları.

Usmanbaş, i. (1974). Müzikte Biçimler, İstanbul: Milli Eğitim Basımevi Devlet Konservatuvarı Yayınları.

\section{Internet Kaynakları}

Altar, C. M. (1993). "Barok Sanat, Barok Müzik ve J. S. Bach Üzerine Araştırma ve Incelemeler (2)", Ders Notları, http://cevadmemduhaltar.com/barok-sanat-2.html /, Erişim tarihi: 30.09.2017 